\title{
Operant performance of rats selectively bred for strong or weak acquisition of conditioned taste aversions
}

\author{
STEPHEN H. HOBBS \\ Augusta College, Augusta Georgia \\ and \\ RALPH L. ELKINS \\ Veterans Administration Medical Center, Augusta, Georgia
}

\begin{abstract}
An ongoing program of selective breeding is successfully developing strains of SpragueDawley-derived rats that are strong or weak acquirers of a cyclophosphamide-induced taste aversion (TA). Although strain separation has been based exclusively upon the TA criterion, all subjects have also been studied with respect to the acquisition of shock-motivated environmental avoidance (SMEA) responses. The separation of strains of strong and weak TA learners has not resulted in similar changes in SMEA learning efficiency. The present study was undertaken to extend this analysis by comparing the two strains on appetitively motivated operant behaviors. Both fixed-ratio (FR) and differential-reinforcement-of-low-rates (DRL) schedules were studied because of their respective contrast with and similarity to the TA paradigm. No strain differences in food-reinforced barpressing were detected under either the FR or the DRL schedule. These results indicate that strain separation on the basis of TA performance is not selecting for generalized learning or performance variables that are common to these tasks. However, in a finding that merits additional study, strong TA conditioners were found to satisfy a criterion for initial barpress acquisition under a continuous schedule of reinforcement in significantly fewer sessions than were required by the weak TA strain.
\end{abstract}

Conditioned taste aversions (TAs) represent a type of learning possessing both theoretical and practical significance (e.g., Bolles, 1973; Elkins, 1975; Garcia \& Ervin, 1968; Gustavson, 1975; Seligman, 1970). TAs are unusually robust adaptive adjustments. They are readily acquired by most subjects of many species, including humans, when distinctive tastes are appropriately paired with natural illness, rotational stimulation, toxic drugs, or X-ray exposure (see Riley \& Tuck, Note 1). However, marked variability in aversion acquisition was characteristic of human alcoholics that were treated with a TA approach to abstinence facilitation (Elkins, 1975, 1980). Comparable individual differences in conditionability likewise have been observed within SpragueDawley-derived rats (Elkins, 1973, 1974). Different strains of rats also vary in efficiency of TA learning (Ader, 1973; Dragoin, 1971; Rozin, 1968). These findings suggest that genotype may contribute to individual differences in TA proneness both within and between populations (Elkins \& Hobbs, 1982). The TA proneness

This work was supported in part by the Medical Research Service of the Veterans Administration. S. H. Hobb's mailing address is: Department of Psychology, Augusta College, Augusta, Georgia 30910. R. L. Elkin's mailing address is: Psychology Research, Veterans Administration Medical Center, Augusta, Georgia 30910. hypothesis has been confirmed through the selective breeding of strains of Sprague-Dawley-derived rats that differ in their propensity toward TA learning (Elkins, Note 2). Significant strain differences in the strength of a cyclophosphamide-induced saccharin aversion appeared in the second selected (S-2) generation, and considerable divergence has occurred over seven selected generations. The objective of selective breeding is the development of phenotypes that will be useful within studies designed to clarify biological bases of individual differences in TA conditionability.

Successful breeding for conditioned avoidance responding has previously demonstrated the usefulness and necessity of determining factors that may or may not be related to the selected trait (e.g., Holland \& Gupta, 1966). For example, a major question concerning the present program of selective breeding is the degree to which strain separation may involve effects that are relatively specific to TA phenomena as opposed to more general learning or performance factors. The neuroanatomical diversity hypothesis of Garcia and Ervin (1968) is relevant to this concern. Garcia and Ervin argue that discrete neural mechanisms subserve the learning of TA and shock-motivated environmental avoidance (SMEA) responses. Some support for this position has been provided by the results of brain-lesion 
experiments that have disrupted primarily one, as opposed to both, of these varieties of learning (Best \& Orr, 1973; Elkins, Fraser, \& Hobbs, 1977; McGowan, Garcia, Ervin, \& Schwartz, 1969; McGowan, Hankins, \& Garcia, 1972).

Because of interest in the neuroanatomical diversity hypothesis, SMEA has also been studied in subjects of all selected generations. However, SMEA has not been a factor in selection, which has been determined exclusively by TA criteria. Consistent with the neuroanatomical diversity hypothesis, strain divergence of TA propensity has not been accompanied by a similar change in efficiency of SMEA learning. Additional investigations of this type are necessary to determine whether attained strain differences are specific to the TA paradigm or reflect other generalized learning/performance factors.

The present study was undertaken to extend this analysis of different learning tasks by comparing the two inbred strains on appetitively motivated operant behaviors. Both fixed-ratio (FR) and differential-reinforcement-of-low-rate (DRL) schedules were selected for study. FR schedules typically sustain high rates of response, and effective DRL performance involves response inhibition. The FR schedule therefore provides a contrast with and the DRL schedule a similarity to the TA paradigm.

\section{METHOD}

The subjects were 90-day-old experimentally naive SpragueDawley-derived rats that had been obtained from the Augusta Veterans Administration Medical Center breeding colony. These animals were second-mating siblings of the S-6 generation of strains that had been selectively bred for either strong or weak TA acquisition. Following breeding for the S-6 generation, S-5 breeders were re-paired with their original partners to produce additional study subjects. The subjects used in this experiment were nine of these second-mating male offspring randomly selected from different pairs of strong-conditioner parents and nine additional males similarly selected from weak-conditioner parents. Individual housing was provided in a temperaturecontrolled room $\left(23^{\circ} \pm 2^{\circ} \mathrm{C}\right)$; lights were turned on at $0600 \mathrm{~h}$ and off at $1800 \mathrm{~h}$. All testing took place during lights-on hours.

Over a 7-day period, the animals were reduced to, and during operant studies were subsequently maintained at, $85 \%$ of their free-feeding weights. Operant testing was conducted in commercial operant chambers that were programmed with standard electromechanical equipment and were located in a room adjacent to the colony room. The subjects were manually shaped to barpress for food pellets (P. J. Noyes Company, $45 \mathrm{mg}$ ) until they had reached a criterion of $\geqslant 75$ responses during each of two consecutive daily 20 -min sessions. When this criterion had been attained by all subjects, one additional session of continuous reinforcement (CRF) was provided, followed by nine sessions providing a reinforcement for every sixth barpress (FR6). Another CRF session was then provided before the animals were switched to a DRL 15 -sec schedule for the remaining nine operant sessions. Under this DRL schedule, only response times greater than or equal to $15 \mathrm{sec}$ were reinforced. DRL efficiency ratios were computed for each session by dividing the sum of responses emitted by the number of earned reinforcements.

For the next 3 weeks the animals were restored to a freefeeding regimen. Confirmation of TA strain differences was begun following $24 \mathrm{~h}$ of fluid deprivation and $3 \mathrm{~h}$ of food deprivation. The subjects were given $15 \mathrm{~min}$ of home-cage access to $0.1 \%$ solution of sodium saccharin in water. Five minutes after re- moval of the saccharin solution, each rat was given a $12.5-\mathrm{mg} / \mathrm{kg}$ ip injection of cyclophosphamide (Cytoxan ${ }^{\circledR}$, Mead Johnson). The subjects were returned to ad-lib food and water $6 \mathrm{~h}$ after injection. Beginning 2 days later, and continuing for 7 days, the animals had constant access to one bottle containing the saccharin solution and another containing plain tap water. Individual saccharin-preference scores were computed by using pre/ post bottle weights to compute the daily percentage to which ingestion of the saccharin solution contributed to total fluid intake.

\section{RESULTS AND DISCUSSION}

Parametric tests were employed to determine group differences on the various measures. The strong-TAconditioning strain was found to reach the barpress criterion in significantly fewer sessions than did the weak conditioners [means $=4.0$ and 5.7 , respectively; $\mathrm{t}(16)=2.24, \mathrm{p}<.05]$. This finding merits additional study within future generations. Nevertheless, no strain effect was found on the number of responses during the CRF session following the shaping process (Figure 1). As can be seen in Figure 1, response rates increased significantly under the FR6 schedule $[F(8,128)=7.90$, $\mathrm{p}<.01$ ] , but no significant simple or interaction effects of strain were obtained. Response rates dropped to preFR levels when the subjects were returned to CRF.

Both strains were inefficient during initial exposures to the DRL schedule (Figure 2), but improved substantially across training sessions $[\mathrm{F}(8,128)=12.93, \mathrm{p}<.01]$. Again, however, no strain effects were observed.

Although both inbred strains developed aversions to the saccharin solution (Figure 3), the avoidance was significantly more pronounced in the strong-conditioning strain of animals $[\mathrm{F}(1,16)=4.70, \mathrm{p}<.05]$. Aversion magnitudes were reduced during the week of extinction

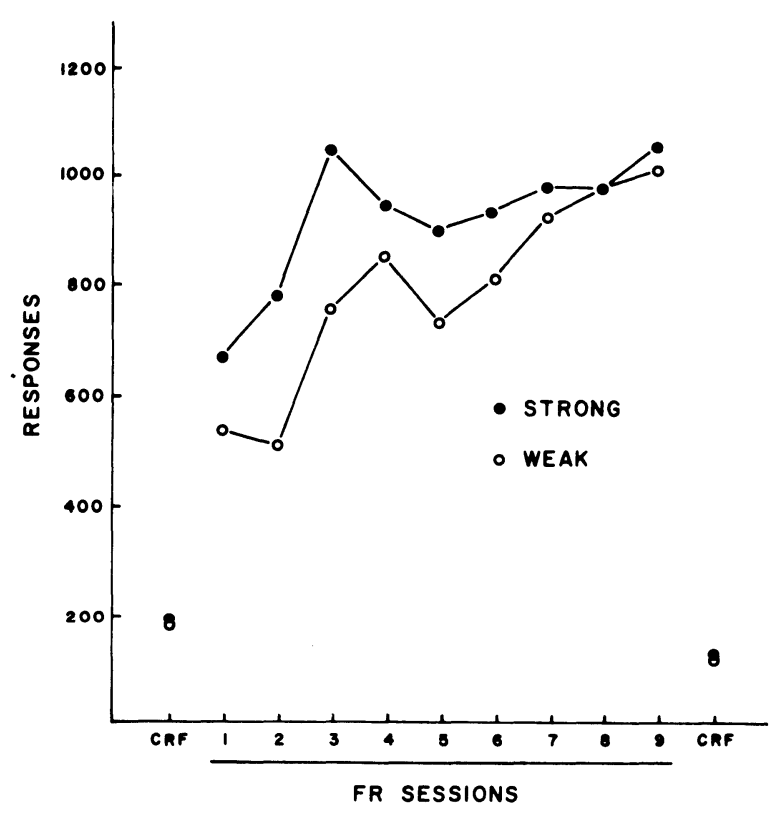

Figure 1. Mean group responses during CRF and FR sessions. 


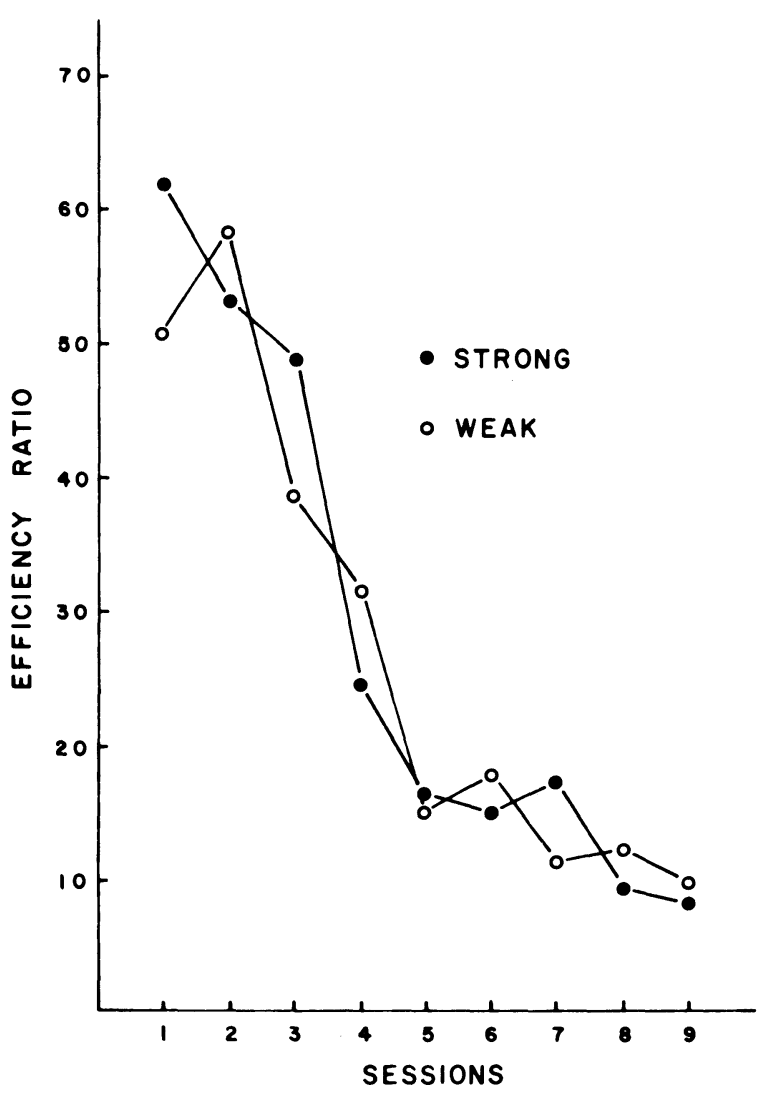

Figure 2. Mean group efficiency ratios during DRL sessions.

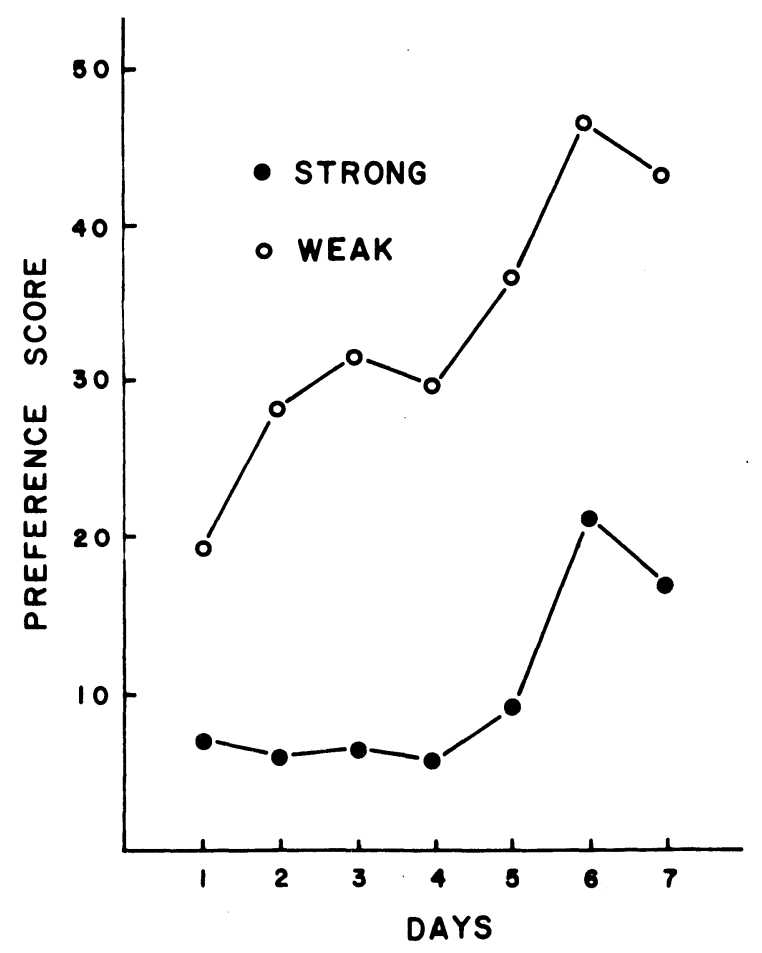

Figure 3. Mean daily group saccharin preference scores following TA conditioning. testing $[F(6,96)=4.13, p<.01]$, but the rate of loss did not interact with strain status.

A correlation matrix for strain, TA preference scores, days to criterion, CRF response rate, FR response rate, and DRL efficiency was generated to assess possible relationships among those variables. As might be expected, small but significant correlations were obtained among some of the operant measures. More importantly, however, these operant measures were not found to correlate significantly with either strain status or TA preference scores.

The results of these different learning paradigms are consistent with the neuroanatomical diversity hypothesis. The FR and DRL results plus the previously described SMEA results indicate that TA strain separation is not simply a specific manifestation of generalized learning or of performance tendencies that extend to these other three paradigms. In direct oppositon to such a general learning/performance hypothesis, these DRL, FR, and SMEA results indicate that the present selectivebreeding program may be exerting effects that are highly specific to TA phenomena. This specificity will be additionally assessed through replication of present findings and studies of new paradigms with subsequent selected generations.

\section{REFERENCE NOTES}

1. Riley, A. L., \& Tuck, D. L. Conditioned taste aversions: A bibliography. Computer printout supplied by A. L. Riley of The American University, Washington, D. C., 1983.

2. Elkins, R. L. Genetically selected taste aversion prone and resistant rats: Implications for studies of individual differences in conditionability and aversion therapy alcoholism treatment. Manuscript submitted for publication, 1983.

\section{REFERENCES}

ADE R, R. "Strain" differences in illness-induced taste aversion. Bulletin of the Psychonomic Society, 1973, 1, 253-254.

BEST, P., \& ORR, J. Effects of hippocampal lesions on passive avoidance and taste aversion conditioning. Physiology \& Behavior, 1973, 10, 193-196.

Bolles, R. C. The comparative psychology of learning: The selective association principle: Some problems with "general" laws of learning. In G. Bermant (Ed.), Perspectives on animal behavior. Glenview, Ill: Scott, Foresman, 1973.

Dragoin, W. B. Conditioning and extinction of taste aversions with variations in intensity of the CS and US in two strains of rats. Psychonomic Science, 1971, 22, 303-304.

Elkins, R. L. Individual differences in bait-shyness: Effects of drug dose and measurement technique. Psychological Record, 1973, 23, 349-358.

Elkins, R. L. Conditioned flavor aversions to familiar tap water in rats: An adjustment with implications for aversion therapy treatment of alcoholism and obesity. Journal of Abnormal Psychology, 1974, 83, 411-417.

Elkins, R. L. Aversion therapy for alcoholism: Chemical, electrical or verbal imaginary. International Journal of the Addictions, 1975, 10, 157-209.

Elxins, R. L. Covert sensitization treatment of alcoholism: Contributions of successful conditioning to subsequent abstinence maintenance. Addictive Behaviors, 1980, 5, 67-89.

Elkins, R. L., Fraser, J., \& HobBs, S. H. Differential olfactory 
bulb contributions to baitshyness and place avoidance learning. Physiology \& Behavior, 1977, 19, 787-793.

Elkins, R. L., \& HobBs, S. H. Taste aversion proneness: A modulator of conditioned consummatory aversions in rats. Bulletin of the Psychonomic Society, 1982, 20, 257-260.

Garcia, J., \& ERvin, R. Gustatory-visceral and telereceptorcutaneous conditioning: Adaptation in internal and external milieus. Communications in Behavioral Biology, 1968, 1, 389-415.

Gustavson, C. R. Taste aversion conditioning of predators. Chronicle of the Horse, 1975, 38, 12-13.

Holland, H. C., \& Gupta, B. D. Some correlated measures of activity and reactivity in two strains of rats selectively bred for differences in the acquisition of a conditioned avoidance response. Animal Behaviour, 1966, 14, 574-580.
McGowan, B., Garcia, J., Ervin, F., \& Schwartz, J. Effects of septal lesions on bait-shyness in the rat. Physiology \& Behavior, 1969, 4, 907-909.

McGowan, B., Hankins, W., \& Garcia, J. Limbic lesions and control of the internal and external environments. Behavioral Biology, 1972, 7, 841-892.

Rozin, P. Specific aversions and neophobia resulting from vitamin deficiency or poisoning in half-wild and domestic rats. Journal of Comparative and Physiological Psychology, 1968, 66, 82-88.

Seligman, M.E.P. On the generality of the laws of learning. Psychological Review, 1970, 77, 406-418.

(Manuscript received for publication April 29, 1983.) 